\title{
ENRAIZAMENTO DE ESTACAS FOLIARES DE VIOLETA-AFRICANA (Saintpaulia ionantha Wendl.) EM DIFERENTES SUBSTRATOS
}

\author{
Rooting of african violet (Saintpaulia ionantha Wendl.) in different substrate
}

\begin{abstract}
José Carlos Lopes ${ }^{1}$, Marilda Torres Capucho ${ }^{2}$, Ruimário Inácio Coelho ${ }^{3}$, Alex Sandro Rodrigues Scandian ${ }^{4}$
RESUMO

O presente trabalho foi conduzido com objetivo de avaliar diferentes substratos no enraizamento de estacas foliares de violeta-africana (Saintpaulia ionantha Wendl). O trabalho foi desenvolvido em casa-de-vegetação, com tela de poliolefina 70\%, no Centro de Ciências Agrárias da Universidade Federal do Espírito Santo, Alegre-ES. Utilizaram-se plantas adultas das cultivares New Mexico (flores lilás); Nancy (flores rosas); Stella (flores azuis) e Mike (flores brancas), que foram aclimatadas; posteriormente, retiraram-se propágulos compostos por uma folha com pecíolo, reduzida a 2/3 do tamanho original, os quais foram esterilizados em solução de hipoclorito de sódio à concentração de 4\%, durante três minutos. Foram utilizados cinco substratos: terra+areia+esterco, areia, pó de xaxim, vermiculita e água destilada, colocados em potes plásticos de $200 \mathrm{~mL}$. O delineamento experimental empregado foi o de blocos ao acaso, com quatro repetições de 10 pecíolos cada. Pelos resultados evidenciou-se que a cultivar Nancy apresentou 100\% de enraizamento em todos os substratos após 40 dias. A maior porcentagem de enraizamento foi obtida em estacas mantidas na água e o melhor desenvolvimento inicial no substrato de pó de xaxim.
\end{abstract}

Termos para indexação: Saintpaulia ionantha, estaquia, propagação.

\section{ABSTRACT}

The present study was accomplished with the objective of evaluate different substrates on the rooting of african violet (Saintpaulia ionantha Wendl). The work was carried out in the greenhouse under a shading net (poliolefinas 70\%) in the Agrarian Science Center of Universidade Federal do Espírito Santo, in Alegre-ES. Were utilized acclimated plants of african violet (Saintpaulia ionantha Wendl), cultivar New Mexico (lilac flowers); Nancy (pink flowers); Stella (blue flowers) e Mike (white flowers). The leaf stalks were reduced to $2 / 3$ of the original size, sterilized with a $4 \%$ sodium hypochloride during three minutes. The substrates utilized were soil+sand+manure, sand, fern fiber dust, vermiculite and water in plastic pot (200 mL). The experimental design was carried out in blocks randomized, with four replications of 10 leaf stalks. The results indicated that cultivar Nancy presented $100 \%$ of rooting in all substrate after 40 days. The greater percentage of rooting was verificated in water and better initial development in fern fiber dust.

Index terms: Saintpaulia ionantha, cuttings, propagation.

(Recebido para publicação em 23 de outubro de 2003 e aprovado em 19 de Janeiro de 2005)

\section{INTRODUÇÃO}

A produção e o comércio de plantas ornamentais têm aumentado desde a década de 80 , e os produtores têm utilizado tecnologias mais modernas, como estufas com controle de umidade, temperatura, irrigação, adubação e iluminação (FABICHAK, 1989).

A violeta-africana (Saintpaulia ionantha Wendl) é considerada uma das mais populares entre as flores envasadas para interior, com centenas de cultivares obtidas de cruzamentos e o surgimento de novas variedades periodicamente (COURTIER \& CLARKE, 1997). É uma planta florífera ornamental originária do leste da África, herbácea, perene, acaule e de fácil cultivo. Pertencente à família Gesneriaceae, da qual cerca de 300 espécies são cultivadas dentre as mais de 2000 conhecidas, com florescimento contínuo durante o ano todo (COURTIER \& CLARKE, 1997; LORENZI \& SOUZA, 1999). Embora possa ser multiplicada por sementes, que é o método propício à obtenção de novas cultivares, sua propagação é feita assexuadamente pelo emprego de estacas foliares compostas por uma folha e seu pecíolo (LORENZI \& SOUZA, 1999; SOARES, 1998; TOMBOLATO, 1993).

Os substratos utilizados para a formação de mudas e mesmo para o cultivo de plantas ornamentais devem ser ricos em nutrientes minerais, apresentar boa estrutura, porosidade, aeração e boa retenção de água.

1. Professor do Departamento de Fitotecnia do Centro de Ciências Agrárias/CCA - Universidade Federal do Espírito Santo/UFES - Caixa Postal 16 29500-000 - Alegre,ES - jclopes@cca.ufes.br

2. Engenheiro Agrônomo Centro de Ciências Agrárias/CCA - UFES - mtorrescapucho@yahoo.com.br

3. Professor do Departamento de Fitotecnia do Centro de Ciências Agrárias/CCA - UFES - rui_mario@uol.com.br

4. Engenheiro Agrônomo formado no Centro de Ciências Agrárias /CCA - UFES - Av. José Júlio de Souza 2190 apto. 1003 - Ed. Port. Alprince-Itaparica Vila Velha, ES - 29102-010 - alscan@terra.com.br 
Também, devem possuir baixa densidade, para facilitar o manuseio e transporte, e devem ser livres de patógenos (HARTMANN \& KESTER, 1968; KÄMPF, 2000). Entre os materiais mais utilizados, a vermiculita vem apresentando destaque tanto isolada como em misturas (LOPES et al., 2003; TOMBOLATO et al., 1987); entretanto, outros substratos, como areia, casca de coco, casca de arroz carbonizada, plantmax ${ }^{\circledR}$, solo, turfa, podem ser empregados desde que apresentem características químicas e físicas favoráveis (COURTIER e CLARKE, 1997; RORIZ, 1994; SCHMITZ et al., 2002; SILVA et al., 2003; SOUZA, 2000).

Com o presente trabalho teve-se como objetivo avaliar diferentes substratos na propagação de quatro cultivares de violeta-africana por meio de estacas foliares.

\section{MATERIAL E MÉTODOS}

O trabalho foi desenvolvido em casa-devegetação, do Departamento de Fitotecnia/ Centro de Ciências Agrárias da Universidade Federal do Espírito Santo (CCA-UFES), em Alegre, Espírito Santo, situada na Mesorregião Sul do Estado, possui coordenadas $20^{\circ} 45^{\prime} 48^{\prime \prime}$ L. S. e $41^{\circ} 31^{\prime} 57^{\prime \prime}$ WGR, apresentando altitude de cerca de $250 \mathrm{~m}$. O clima predominante é quente e úmido no verão com inverno seco, com precipitação anual média de $1200 \mathrm{~mm}$, com maior concentração de novembro a março (60 a 70\%). A temperatura média anual gira em torno de $23^{\circ} \mathrm{C}$, e as máximas diárias nos meses mais quentes, dezembro a abril oscilam em torno de $29^{\circ} \mathrm{C}$ e as mínimas, em torno de $20^{\circ} \mathrm{C}$ nos meses mais frios, junho a agosto (ESPÍRITO SANTO, 1994).

Foram utilizadas estacas foliares de violetaafricana (Saintpaulia ionantha Wendl), com $10 \mathrm{~cm}$ de comprimento, das cultivares New Mexico (flores lilás); Nancy (flores rosas); Stella (Flores azuis) e Mike (flores brancas), oriundas da Cooperativa de Produtores de Flores da cidade de Holambra, São Paulo. Visando à aclimatação, as plantas foram mantidas em casa-devegetação coberta com tela de poliolefina $70 \%$, acondicionadas sobre mesas com armação feita com outra tela sombrite de $40 \%$ a $1,20 \mathrm{~m}$ de altura. As regas foram feitas diariamente, de acordo com a necessidade das plantas. O comportamento das plantas foi avaliado diariamente, durante 60 dias, observando-se aparecimento de doenças, deficiências nutritivas, taxa de sobrevivência, altura e diâmetro médio da planta, diâmetro da maior e da menor folha, comprimento do maior e do menor folíolo.

No estudo do enraizamento, foram utilizados pecíolos intactos de folhas de violeta retirados das plantas aclimatadas, com as folhas reduzidas a 2/3 do tamanho original e esterilizados em solução de hipoclorito de sódio a 4\% durante três minutos. Posteriormente, foram colocados para enraizar em potes de plástico com capacidade para $200 \mathrm{~mL}$, contendo os substratos terra+areia+esterco (relação 1:1:1) areia, pó de xaxim, vermiculita e água, num fatorial 4 x 5 (quatro cultivares e cinco substratos). Os experimentos foram mantidos em casa-de-vegetação, sob tela de poliolefina $70 \%$ e a reposição de água de acordo com a necessidade das plantas, avaliada com base na evaporação do tanque classe A. Quando se utilizou água como substrato, essa foi destilada, mantida em potes plásticos com tampas perfuradas no centro, onde os pecíolos foram introduzidos e a cada 48 horas era feita a troca da água nos recipientes. O delineamento experimental foi o de blocos ao acaso, com quatro repetições de dez pecíolos. As avaliações foram feitas durante um período de 190 dias após o plantio, por meio dos parâmetros: porcentagem de enraizamento, comprimento médio de raízes, número médio de raízes emitido por folíolo, número médio de folíolos, número de brotos emitidos, comprimento dos folíolos e área foliar.

\section{RESULTADOS E DISCUSSÃO}

Na Tabela 1 verificam-se os resultados das análises relativas ao comportamento das plantas de violeta imediatamente e após 60 dias ao início do período de aclimatação em Alegre-ES. Não se verificaram diferenças acentuadas entre os parâmetros avaliados, indicando boa aclimatação das plantas ao longo do período analisado. Possivelmente esse comportamento esteja associado às baixas oscilações, relativamente, das condições climáticas ocorridas durante o período de condução do trabalho (Figura 1). Entretanto, após 30 dias, verificou-se a ocorrência de folhas quebradiças, e de coloração amarronzada, em todos os cultivares, com destaque para o cv. Mike, fator que foi corrigido com a utilização de adubo formulado, conforme Tabela 2, na proporção de $2,5 \mathrm{~g} \mathrm{~L}^{-1}$ de água, dosagem de $50 \mathrm{~mL}$ planta ${ }^{-1}$, a cada 15 dias. Após 32 dias, verificou-se a ocorrência de algumas folhas com início de formação de bolor cinza, determinando nas folhas a perda de consistência e uma coloração amarronzada, cujo fungo isolado foi caracterizado como Botrytis cinerea Pers. ex Fr., causador do mofo-cinzento, que foi controlado pela aplicação de óxido cloreto de cobre a $2 \%$, conforme recomendações feitas pela análise no Laboratório de Fitossanidade da UFES. 
TABELA 1 - Taxa de sobrevivência (TS), altura (H), diâmetro da planta (DP), área da maior (S1) e da menor (S2) folha e comprimento do maior (C1) e do menor (C2) folíolo de plantas de violeta recém-adquiridas e após 60 dias de aclimatação. CCA-UFES, Alegre, ES, 2002.

\begin{tabular}{|c|c|c|c|c|c|c|c|}
\hline \multirow[b]{2}{*}{ Cultivares } & \multicolumn{7}{|c|}{ Dados iniciais } \\
\hline & $\begin{array}{l}\text { TS } \\
\text { (\%) }\end{array}$ & $\begin{array}{c}\mathbf{H} \\
(\mathbf{m m})\end{array}$ & $\begin{array}{c}\text { DP } \\
\left(\mathbf{m m}^{2}\right)\end{array}$ & $\begin{array}{c}\mathrm{S} 1 \\
\left(\mathrm{~mm}^{2}\right)\end{array}$ & $\begin{array}{c}\mathrm{S} 2 \\
\left(\mathrm{~mm}^{2}\right)\end{array}$ & $\begin{array}{c}\text { C1 } \\
(\mathrm{mm})\end{array}$ & $\begin{array}{c}\mathrm{C} 2 \\
(\mathrm{~mm})\end{array}$ \\
\hline New Mexico & 100 & 12,32 & 1411 & 2891 & 2,45 & 7,4 & 2,6 \\
\hline Nancy & 100 & 13,11 & 1407 & 2680 & 6,97 & 9,0 & 3,8 \\
\hline Stella & 100 & 13,69 & 1523 & 26,68 & 5,46 & 6,2 & 4,0 \\
\hline \multirow[t]{2}{*}{ Mike } & 100 & 12,97 & 1494 & 23,10 & 3,15 & 7,5 & 2,1 \\
\hline & \multicolumn{7}{|c|}{ Dados após 60 dias } \\
\hline Cultivares & $\begin{array}{l}\text { TS } \\
(\%)\end{array}$ & $\begin{array}{c}\mathbf{H} \\
(\mathbf{m m})\end{array}$ & $\begin{array}{c}\text { DP } \\
\left(\mathrm{mm}^{2}\right)\end{array}$ & $\begin{array}{c}\mathrm{S} 1 \\
\left(\mathrm{~mm}^{2}\right)\end{array}$ & $\begin{array}{c}\mathrm{S} 2 \\
\left(\mathrm{~mm}^{2}\right)\end{array}$ & $\begin{array}{c}\text { C1 } \\
(\mathrm{mm})\end{array}$ & $\begin{array}{c}\mathrm{C} 2 \\
(\mathrm{~mm})\end{array}$ \\
\hline New Mexico & 100 & 13,71 & 1426 & 2780 & 3,12 & 9,5 & 2,9 \\
\hline Nancy & 100 & 15,19 & 1390 & 2703 & 2,68 & 9,8 & 3,4 \\
\hline Stella & 100 & 13,88 & 1506 & 25,42 & 3,89 & 5,33 & 2,7 \\
\hline Mike & 100 & 14,57 & 1499 & 24,04 & 2,85 & 9,3 & 3,9 \\
\hline
\end{tabular}
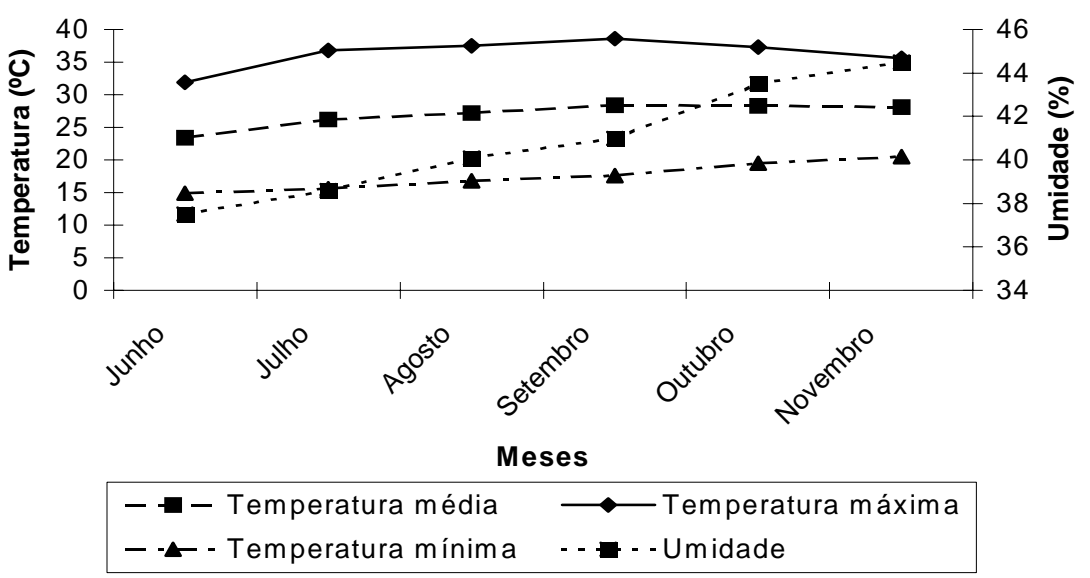

FIGURA 1 - Temperatura e umidade relativa média durante o período de condução do experimento. CCA-UFES, Alegre, ES, 2002. 
LOPES, J. C. et al.

TABELA 2 - Composição química (\%) do adubo adicionado aos substratos utilizados para o plantio de pecíolos de violeta-africana. CCA-UFES, Alegre, ES, 2002.

\begin{tabular}{|c|c|c|c|c|c|c|c|c|}
\hline Elemento & $\begin{array}{c}\text { Nitrogênio } \\
\text { (N) }\end{array}$ & $\begin{array}{c}\text { Fósforo } \\
\left(\mathbf{P}_{2} \mathbf{O}_{5}\right)\end{array}$ & $\begin{array}{c}\text { Potássio } \\
\left(\mathbf{K}_{2} \mathbf{O}\right)\end{array}$ & $\begin{array}{c}\text { Enxofre } \\
\left(\mathrm{SO}_{4}\right)\end{array}$ & $\begin{array}{c}\text { Magnésio } \\
\text { (Mg) }\end{array}$ & $\begin{array}{c}\text { Zinco } \\
\text { (Zn) }\end{array}$ & $\begin{array}{c}\text { Boro } \\
\text { (B) }\end{array}$ & $\begin{array}{c}\text { Cloro } \\
\text { (Cl) }\end{array}$ \\
\hline $\begin{array}{c}\text { Concentração } \\
\text { (\%) }\end{array}$ & 15,00 & 5,00 & 20,00 & 2,00 & 0,085 & 0,07 & 0,03 & 1,00 \\
\hline
\end{tabular}

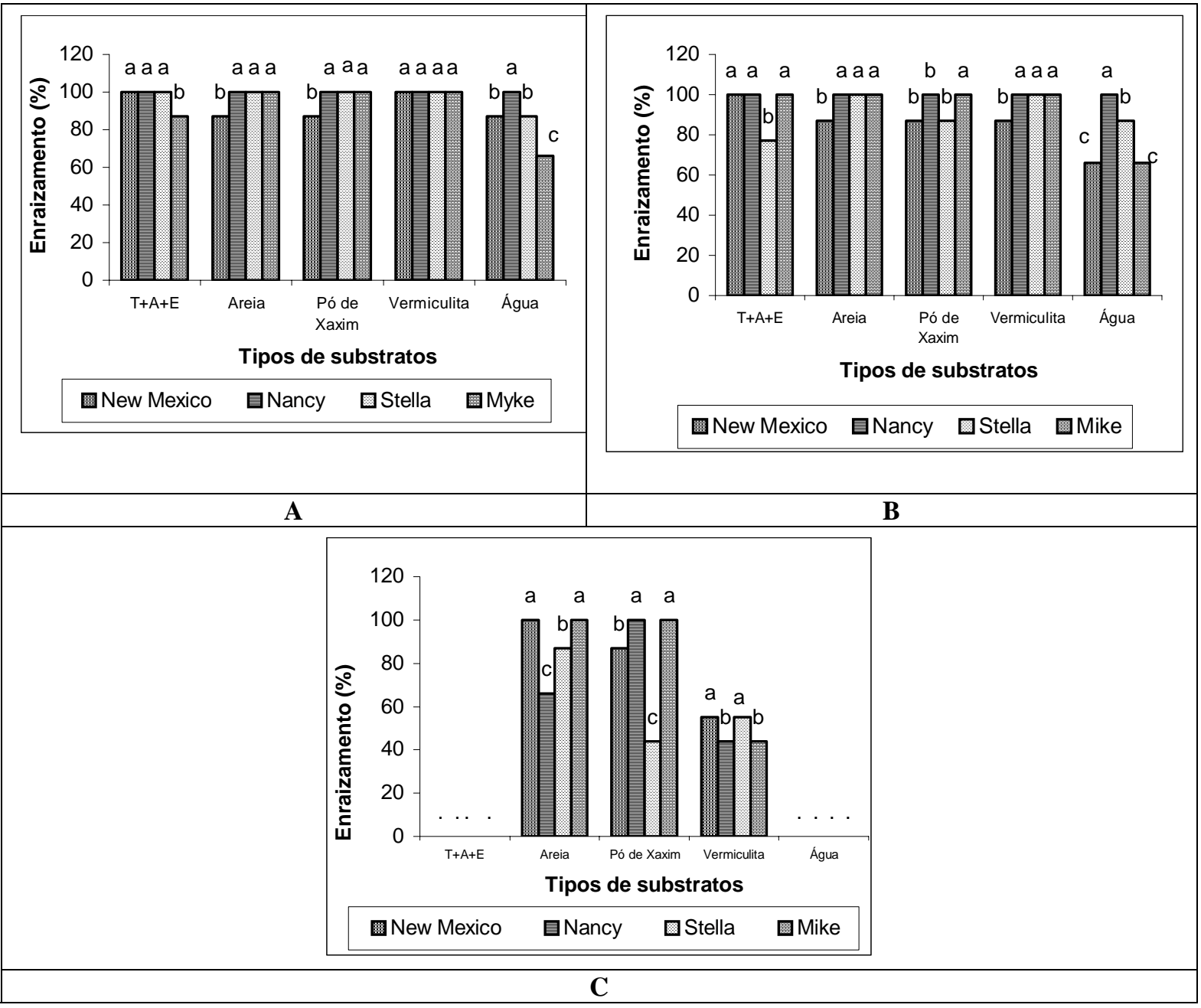

FIGURA 2 - Porcentagem de enraizamento de pecíolos de violeta-africana cultivares New Mexico, Nancy, Stella e Mike africana aos 40 (A), 60 (B) e 190 (C) dias após o plantio em diferentes substratos. CCA-UFES, Alegre-ES, 2002. 
Os resultados de enraizamento obtidos em todos as cultivares, nos diferentes substratos utilizados, encontramse na Figura 2. A cultivar Nancy, após 40 dias do plantio, apresentou $100 \%$ de enraizamento, seguindo-se as cultivares Stella e New Mexico, com 94 e 90\%, respectivamente, e o Mike, com $75 \%$ de enraizamento. Após esse período, até o final do experimento, com 190 dias, verificou-se que a cultivar Nancy, seguida da cultivar Stella, apresentaram-se mais adaptadas, com melhor desenvolvimento do que as cultivares New Mexico e Mike, principalmente quando avaliado o comprimento de raízes (Figura 3). O comprimento médio e o número de raízes emitidas apresentados nas Figuras 3 e 4 evidenciam que estacas colocadas em água foram as que apresentaram melhores resultados, sugerindo ser o melhor substrato para proceder ao enraizamento numa fase inicial de pecíolos dessas cultivares. Entretanto, após 60 dias houve deterioração do sistema radicular, culminando com a morte das plântulas. Ao final do experimento, verificou-se melhor desenvolvimento das plântulas mantidas no substrato pó-de-xaxim (Figuras 5, 6 e 7), em que se verificou maior número de folíolos, maior número médio de brotos e maior comprimento dos folíolos, tendo sido verificado ainda que, além de melhor desenvolvimento, as plântulas apresentaram maior área foliar (Figura 8). Pelos resultados, evidenciou-se ainda que o comprimento médio dos folíolos foi maior nas cultivares New México, Nancy, Mike, em relação à cultivar Stella.

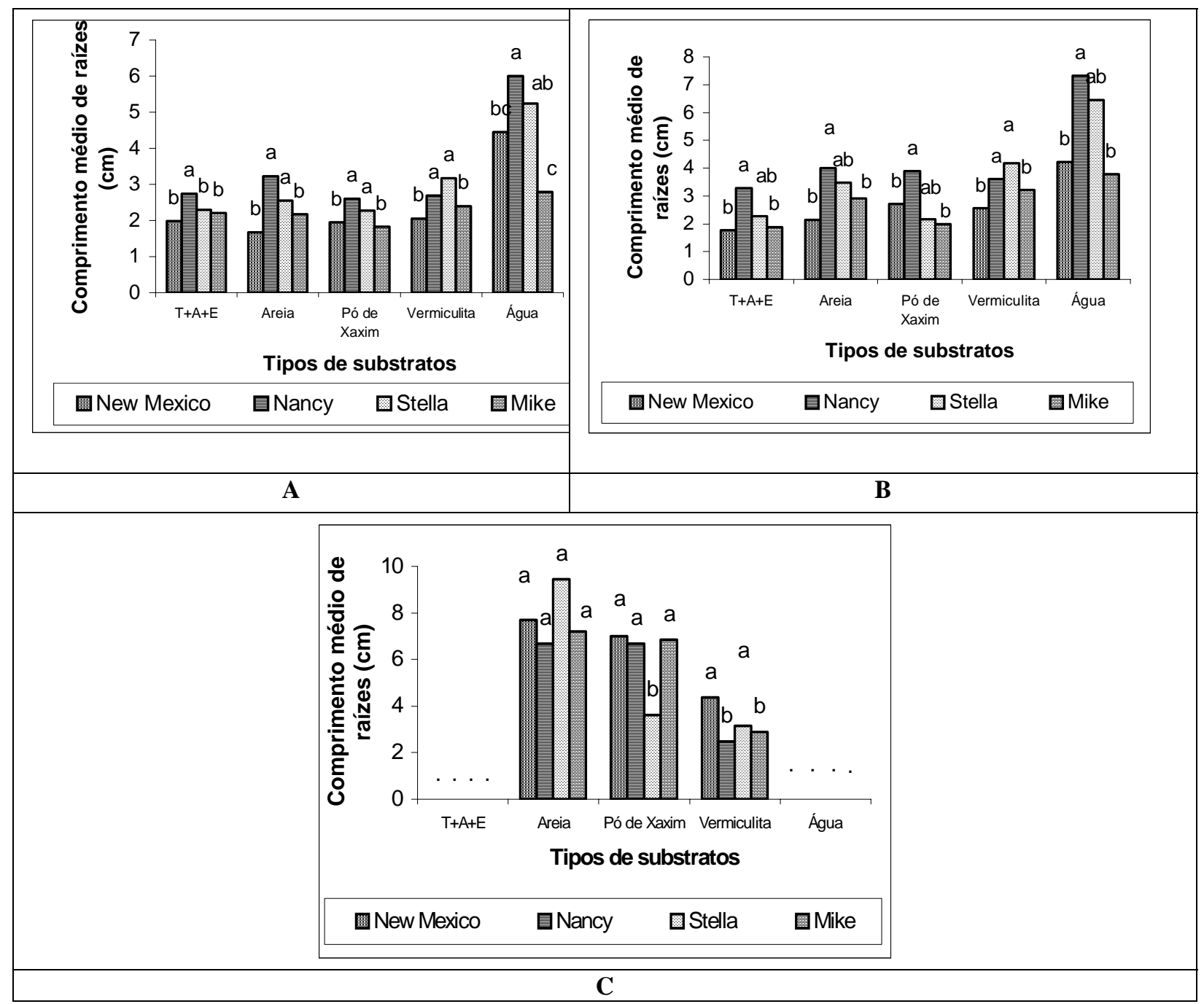

FIGURA 3 - Comprimento médio de raízes (cm) em pecíolos de violeta-africana cultivares New Mexico, Nancy, Stella e Mike aos 40 (A), 60 (B) e 190 (C) dias em diferentes substratos. CCA-UFES, Alegre-ES, 2002. 


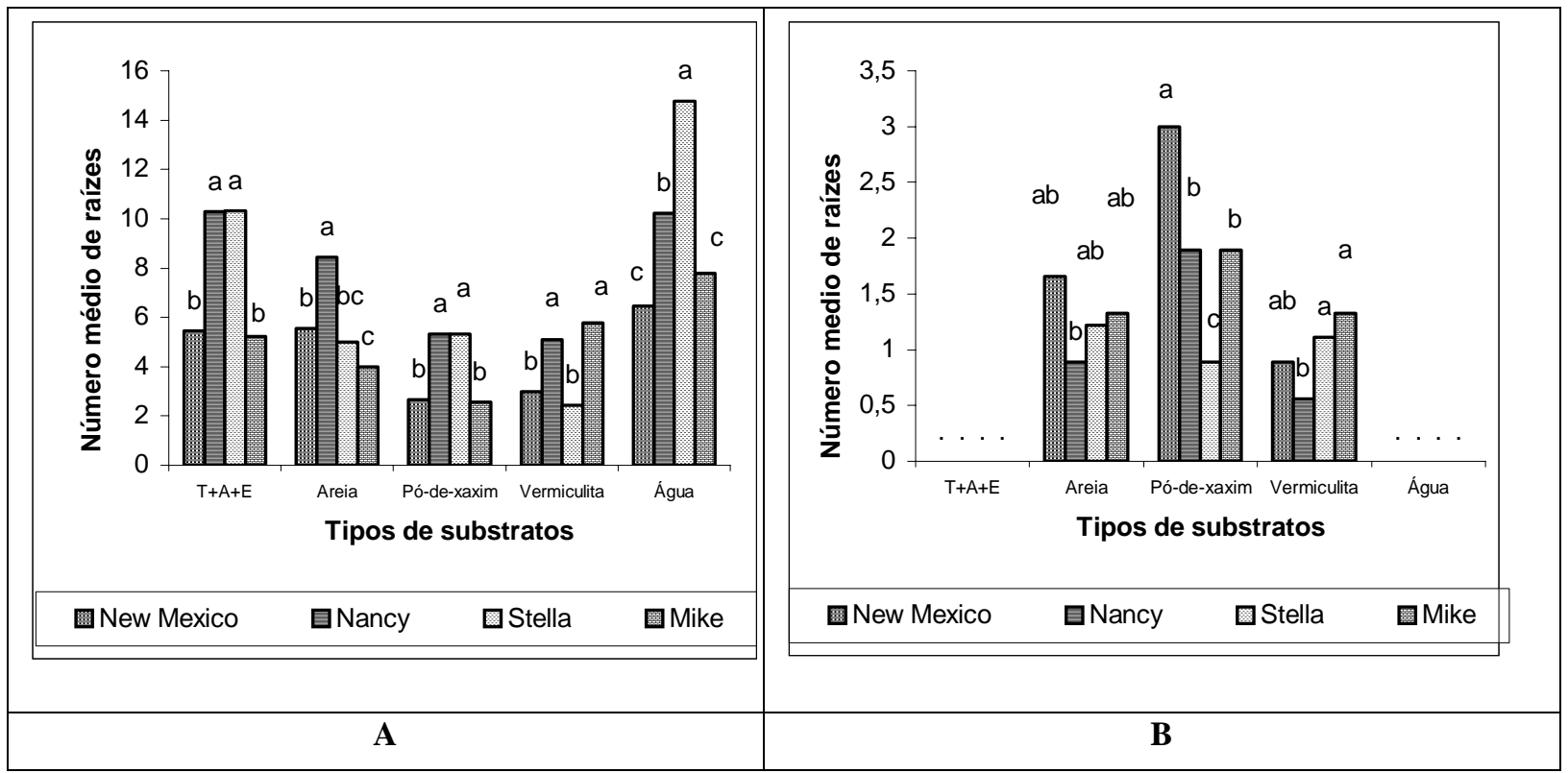

FIGURA 4 - Número médio de raízes em pecíolos de violeta-africana cultivares New Mexico, Nancy, Stella e Mike aos 40 (A), e 190 (B) dias após o plantio em diferente substratos. CCA-UFES, Alegre-ES, 2002.

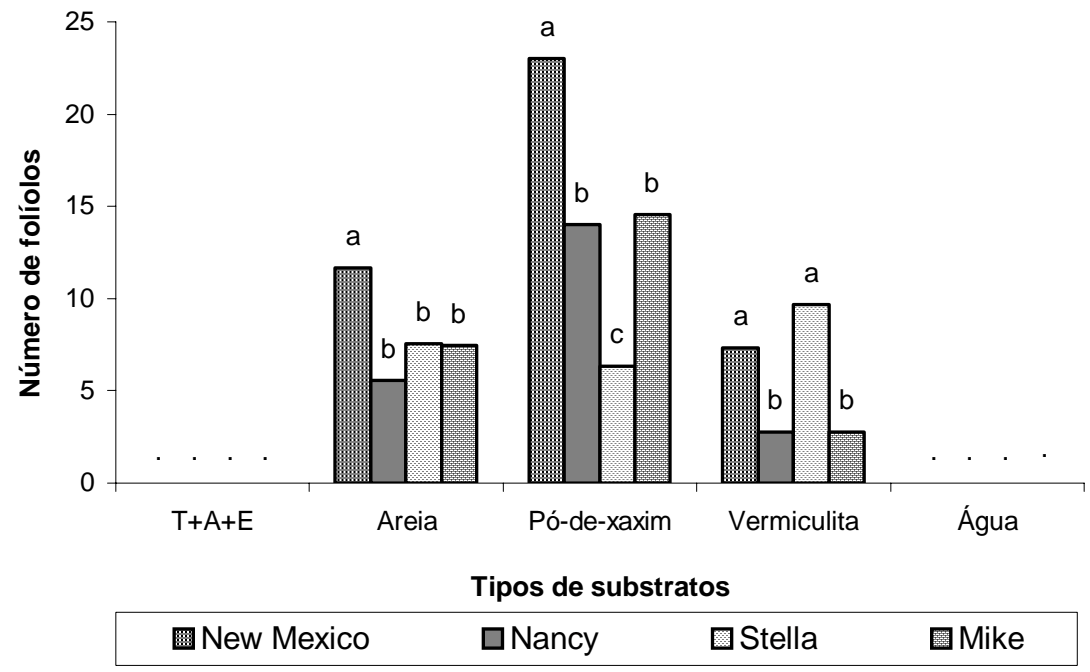

FIGURA 5 - Número médio de folíolos de violeta-africana, cultivares New Mexico, Nancy, Stella e Mike, aos 190 dias após o plantio em diferentes substratos. CCA-UFES, Alegre-ES, 2002. 


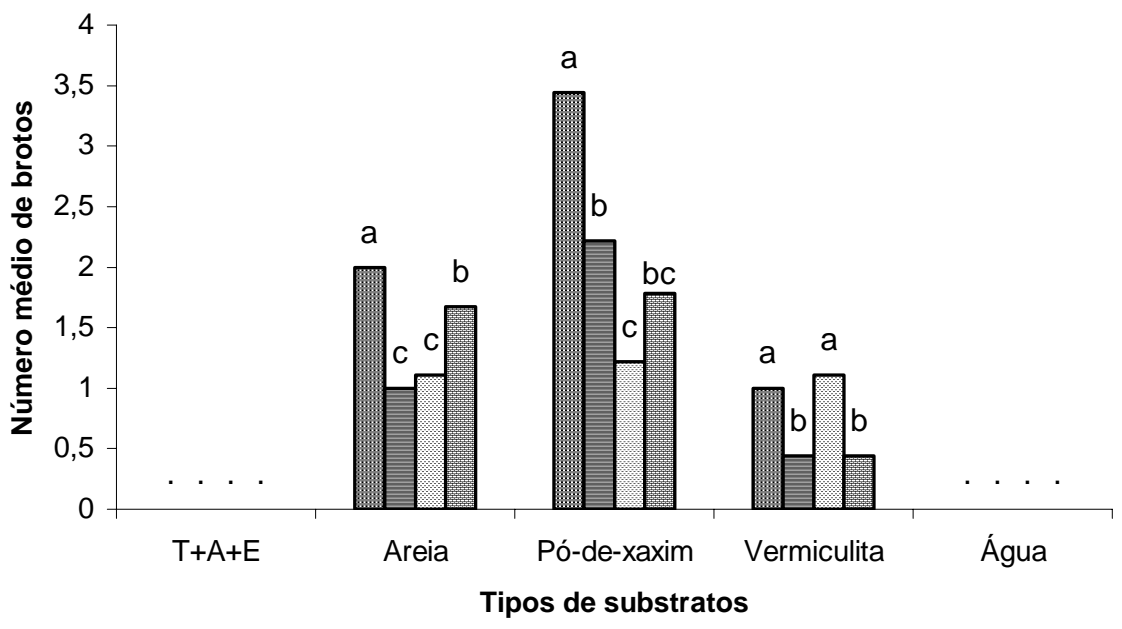

$\square$ New Mexico

目Nancy

$\square$ Stella

$\square$ Mike

FIGURA 6 - Número médio de brotos de violeta-africana, cultivares New Mexico, Nancy, Stella e Mike, aos 190 dias após o plantio em diferentes substratos. CCA-UFES, Alegre-ES, 2002.

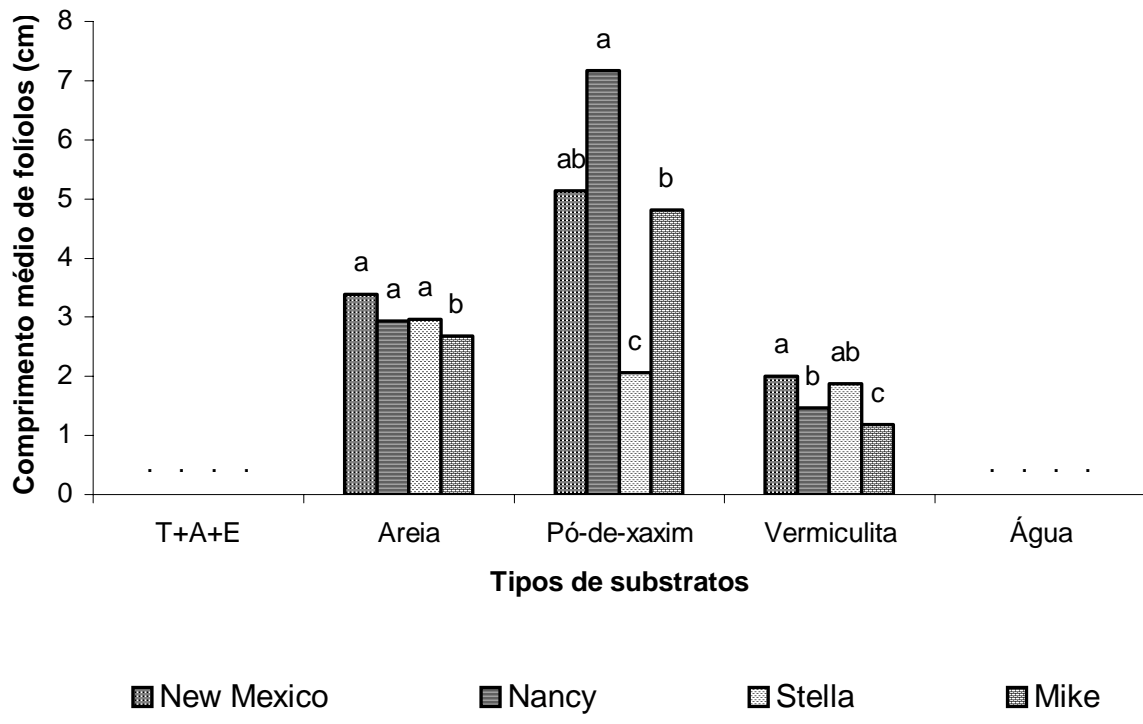

FIGURA 7 - Comprimento médio de folíolos de violeta-africana, cultivares New Mexico, Nancy, Stella e Mike, aos 190 dias após plantio em diferentes substratos. CCA-UFES, Alegre-ES, 2002. 


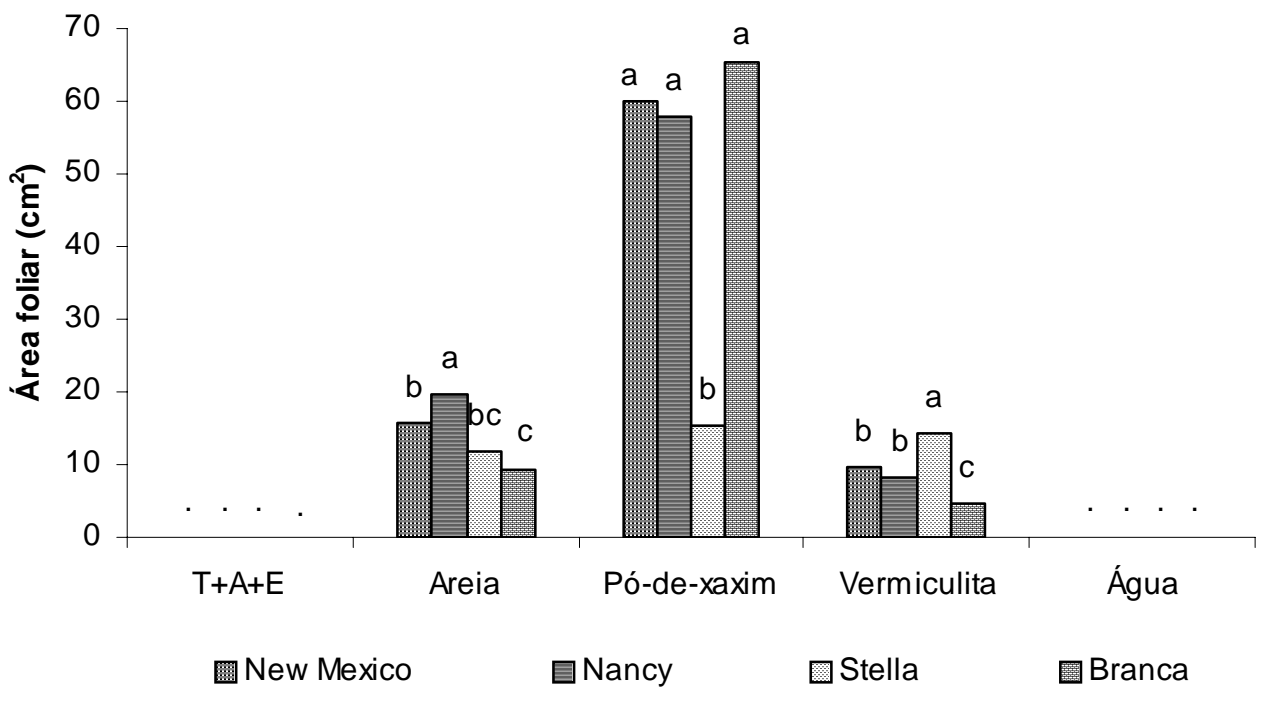

FIGURA 8 - Área foliar de violeta-africana, cultivares New Mexico, Nancy, Stella e Mike, aos 190 dias após o plantio em diferentes substratos. CCA-UFES, Alegre-ES, 2002.

Analisando os substratos isoladamente, observa-se que a areia proporcionou maior porcentagem de pecíolos enraizados. No entanto, a água permite a obtenção de plantas com sistema radicular de melhor qualidade, uma vez que os pecíolos enraizados em água emitiram maior número de raízes e raízes mais longas. Os melhores resultados obtidos nesses dois substratos possivelmente estão associados ao melhor arejamento proporcionado pela troca periódica da água e pela própria constituição da areia. De acordo com Kämpf (2000), no enraizamento de estacas de crisântemos e roseiras, a casca de arroz carbonizada comportou-se como melhor substrato, devido à baixa densidade, capacidade de retenção de água, boa aeração e drenagem rápida. Bosa et al. (2003), trabalhando com crescimento de gipsofila em diferentes substratos, obtiveram maior enraizamento ex vitro em substrato com alto espaço de aeração. De acordo com Coutinho \& Carvalho (1983), o substrato apropriado deve ser de baixa densidade, rico em nutrientes, composição química equilibrada e física uniforme, com boa aeração e drenagem, boa coesão entre as partículas e raízes, estar isento de plantas daninhas e provido de boa flora bacteriana. Como citado anteriormente, o melhor desenvolvimento de parte aérea se deu em pó de xaxim, significando que os pecíolos devem ser enraizados em água e transplantados para o pó de xaxim para seu melhor desenvolvimento. Pode-se atribuir essas diferenças ao tipo de substrato utilizado, levando-se em conta que as condições ambientais foram extremamente homogêneas e possivelmente ideais em relação à temperatura $\left(24 \pm 5^{0} \mathrm{C}\right)$ e umidade relativa em torno de $70 \%$ na casa-de-vegetação. Muitos substratos têm sido testados, tais como vermiculita, areia e terra (KÄMPF, 1999; SOUZA, 2002; TAkeyoshi et al., 1984; Tombolato et al., 1987; Tombolato, 1993) e os resultados obtidos geralmente apresentam grandes variações em função da própria espécie em estudo e outros fatores, como idade e vigor (Alvarenga \& Carvalho, 1983; Pádua, 1983). Maciel et al. (2000), trabalhando com aclimatação de plantas de violeta obtidas in vitro, obtiveram 100\% de sobrevivência das plântulas em todas as combinações de substratos utilizadas, sugerindo que a mistura de substratos proporciona melhores características físicas, químicas e biológicas em relação aos substratos isolados. De outra forma, embora o pó de xaxim tenha se comportado como o melhor substrato para transplantio e desenvolvimento das mudas de violeta, é um substrato cuja utilização apresenta restrições, devido à sua proibição no mercado, fator que sugere novos estudos utilizando outras alternativas de substratos. 


\section{CONCLUSÕES}

a) A cultivar Nancy apresentou $100 \%$ de enraizamento após 40 dias do plantio;

b) Maior número e comprimento de raízes foi obtido no substrato água;

c) O substrato de pó de xaxim foi o que propiciou o maior número de folíolos, maior número médio de brotos e maior comprimento de folíolos;

d) As plantas de violetas-africanas devem ser enraizadas inicialmente em água e posteriormente transplantadas para pó de xaxim, ou outro substrato similar;

e) Para enraizamento de pecíolos de violeta nos substratos terra+areia+esterco e em água, recomenda-se um período máximo de 60 dias.

\section{REFERÊNCIAS BIBLIOGRÁFICAS}

ALVARENGA, L. R.; CARVALHO, V. D. Uso de substâncias promotoras de enraizamento de estacas frutíferas. Informe Agropecuário, Belo Horizonte, v. 9, n. 101, p. 47-55, 1983.

BOSA, N. et al. Crescimento de mudas de gipsofila em diferentes substratos. Horticultura Brasileira, Brasília, v. 21, n. 3, p. 514-519, jul./set. 2003.

COURTIER, J.; CLARKE, G. O grande livro das plantas de interior: guia essencial para a escolha e a manutenção das plantas de interior. São Paulo: Livros e Livros, 1997. 240 p.

COUTINHO, M.; CARVALHO, E. J. M. Caracterização das propriedades de alguns substratos para propagação de mudas. Bragantia, Campinas, v. 14, p. 167-176, 1983.

ESPÍRITO SANTO. Secretaria de Estado de Ações Estratégicas e Planejamento. Departamento Estadual de Estatística. Informações municipais do Estado do Espírito Santo: 1994. Vitória, 1994. v. 1, 803 p.

FABICHAK, I. Plantas de vasos e jardins. 3. ed. São Paulo: Nobel, 1989. 98 p.

HARTMANN, H. T.; KESTER, E. D. Plant propagation. 2. ed. New Jersey: Prentice Hall, 1968. 702 p.
KÄMPF, A. N. Seleção de materiais para uso como substratos. In: KÄMPF, A. N.; FERMINO, M. H. Substratos para plantas: a base da produção vegetal em recipientes. Porto Alegre: Gênesis, 1999. p. 139146.

KÄMPF, A.N. Produção comercial de plantas ornamentais. Guaíba: Agropecuária, 2000. 254 p.

LOPES, J. C. et al. Influência do ácido indol-3-butírico e do substrato no enraizamento de estacas de acerola. Revista Brasileira de Agrociência, Pelotas, v. 9, n. 1, p. 79-83, 2003.

LORENZI, H.; SOUZA, H. M. Plantas ornamentais do Brasil: arbustivas, herbáceas e trepadeiras. 2. ed. Nova Odessa: Plantarum, 1999. 1088 p.

MACIEL, A. L. R.; SILVA, A. B.; PASQUAL, M. Aclimatação de plantas de violeta (Saintpaulia ionantha Wedl) obtidas in vitro: efeito do substrato. Ciência Agrotécnica, Lavras, v. 24, n. 1, p. 9-12, jan./mar. 2000.

PÁDUA, T. Propagação das árvores frutíferas. Informe Agropecuário, Belo Horizonte, v. 9, n. 101, p. 11-19, 1983.

RORIZ, A. Violetas. Revista dos Amantes da Natureza, São Paulo, 1994.

SCHMITZ, J. A. K.; SOUZA, P. V. D.; KAMPF, A. N. Propriedades químicas e físicas de substratos de origem mineral e orgânica para o cultivo de mudas em recipientes. Ciência Rural, Santa Maria, v. 32, n. 6, p. 937-944, 2002.

SILVA, A. B. et al. BAP e substratos na aclimatização de plântulas de gloxínia (Sinningia speciosa Lood. Hiern.) provenientes de culturas de tecidos. Ciência e Agrotecnologia, Lavras, v. 27, n. 2, p. 255-260, mar./abr. 2003.

SOARES, M. P. Verdes urbanos e rurais: orientação para arborização de cidades e sítios campesianos. Porto Alegre: Cinco Continentes, 1998. 242 p.

SOUZA, N. A. Utilização da casca de coco para produção de tutores tipo xaxim e substrato para cultivo de Syngonium angustatum Schott. 2002. 81 f. Dissertação (Mestrado) - UENF, Campos, 2002. 
TAKEYOSHI, N. I. et al. Efeitos de diversos substratos no enraizamento de estacas de Chrysanthemum morifolium cV polaris. In: CONGRESSO BRASILEIRO DE FLORICULTURA E PLANTAS ORNAMENTAIS, 4., 1983, Rio de Janeiro. Anais... Brasília: Sociedade Brasileira de Floricultura e Plantas Ornamentais/EMBRAPA, 1984. p. 280.

TOMBOLATO, A. F. C. Cultivo comercial de violetaafricana. Boletim técnico do Instituto Agronômico,
Campinas, n. 140, jan. 1993.

TOMBOLATO, A. F. C. et al. Tipos de substrato para formação de mudas de violeta-africana (Saintpaulia ionantha $\mathrm{H}$. Wendl.). In: CONGRESSO BRASILEIRO DE FLORICULTURA E PLANTAS ORNAMENTAIS, 6., 1987, Campinas-SP. Programa e resumos... Campinas: Instituto Agronômico, 1987. 
